\title{
Sex Influence on the Formation of Alcohol Preference and Behavior in Rats during the Long-Term Caffeine and Ethanol Intake
}

\author{
Eugenia Kutcher ${ }^{1,2}$, Alexey Egorov ${ }^{1,2}$, Elena Filatova ${ }^{1}$, Kristina Kulagina ${ }^{1}$, Nadezhda Chernikova ${ }^{1}$ \\ ${ }^{1}$ Behavior Neurophysiology and Pathology Laboratory, IM Sechenov Institute of Evolutionary Physiology \\ and Biochemistry, Russian Academy of Sciences, St. Petersburg, Russia \\ ${ }^{2}$ Department of Psychiatry and Addictions, Medical Faculty, St. Petersburg State University, \\ St. Petersburg, Russia \\ E-mail: draegorov@mail.ru
}

Received March 23, 2011; revised April 11, 2011; accepted May 4, 2011

\begin{abstract}
Last years the intake of energy drinks (drinks containing caffeine and alcohol) both in young men and women has been increased. However the investigators do not pay attention to the analysis of gender differences. The goal of the study was the investigation of ethanol and caffeine influence on the alcohol preference formation and behavior in male and female rats under the conditions of long-term experiment. It has been found that six month intake of caffeine, ethanol and their combination has led to the increase of alcohol preference both in male and female rats. Alcohol preference was formed earlier in rats consumed combination of caffeine with ethanol, later on in rats consumed ethanol. In animals consumed caffeine the strong alcohol preference did not form up to the end of the experiment. Alcohol preference was higher in female rats consuming caffeine with ethanol and pure ethanol solution compared to male rats. Behavioral activity significantly increased in females consumed caffeine and caffeine with ethanol, compared to animals received ethanol and controls. Similar tendency was observed in male rats. The anxiety level was significantly higher in females rats in all experimental groups compared to controls, while males did not demonstrate increased anxiety.
\end{abstract}

Keywords: Ethanol, Caffeine, Two-Bottle Test, Behavioral Activity, Anxiety

\section{Introduction}

According to epidemiological data, up to $80 \%$ consumed alcoholic beverages in Russia is beer and light alcoholic beverages. It happens not due to replacement of strong liquors, but because of alcohol consumption increase per capita [1]. Beer and light alcoholic beverages, including energy drinks, are very popular among young generation, both in Russian males and females [2]. In the US the ingestion of energy drinks in combination with alcohol is becoming increasingly popular [3,4], with $24 \%$ of a large stratified sample of college students reporting such consumption within the past 30 days [3].

There is an association between the heavy use of caffeine and the heavy use of alcohol $[5,6]$. The effects of energy drinks which contain both ethanol and caffeine are not good investigated especially after long term intake. One study showed that ingestion of a caffeinated energy drink (Red Bull) with vodka reduced participants perception of impairment of motor coordination in comparison to vodka alone, but did not significantly reduce objective measures of alcohol-induced impairment of motor coordination, reaction time, or breath alcohol concentration [7]. Thus, when mixing energy drinks and alcohol, users may not feel the symptoms of alcohol intoxication. This may increase the potential for alcoholrelated injury [8]. In addition, mixing energy drinks with alcohol was associated with increased heavy episodic drinking and episodes of weekly drunkenness [3] and closely associated with a problem behavior syndrome [9]. In recent publication Arria with colleagues [10] insist that weekly or daily energy drink consumption is strongly associated with alcohol dependence Besides, energy drink consumption significantly predicted subsequent nonmedical prescription stimulant use [11].

Data on the combined effects of caffeine and ethanol 
in acute animal experiments are controversial $[12,13]$. It was shown in mice that a single dose caffeine administration only masks alcoholic intoxication, but did not compensate the ethanol induced cognitive impairments [14], as it has been previously observed [15,16]. In was demonstrated that the administration of energy drink alone has increased the locomotor activity of mice in relation to a control group. Low doses of ethanol alone or in combination with energy drink did not affect their locomotor activity. However, the reduction of activity observed after high doses of ethanol was antagonized by energy drink [17].

However, few and controversial empirical studies to date have examined the demographics of energy drink consumption, particularly with respect to gender differences in the prevalence or correlates of consumption. It was supposed that young males are the main consumers of beverages containing caffeine and alcohol [18]. In a survey of 1253 college students, energy drink users were disproportionately male and consumed alcohol more frequently than non-energy drink users [11]. Temple with colleagues [19] have suggested that boys are more sensitive to the effects of caffeine than girls. Meanwhile, another publication reported about higher rates of consumption in female students than in male students [20]. Epidemiological date have shown the increase in beer and soft drink consumption in adolescents and young females as well [1]. Besides, clinical investigations have demonstrated both young males and female preponderance to light beverages $[21,22]$. We did not find out animal experimental studies on combined ethanol and caffeine intake with respect to gender peculiarities.

The aim of the study was the investigation of ethanol and caffeine influence on alcohol preference formation and behavior in male and female rats under the conditions of long-term experiment.

\section{Materials and Methods}

The study was was conducted on 60 adult Wiatar rats: 30 males and 30 females. The animals were kept on a standard diet. Rats were divided into four groups. Within 6 months of the experiment the first group had access only to a solution containing $10 \%$ ethanol and $0.4 \mathrm{~g} / \mathrm{l}$ of caffeine, the second group - only $10 \%$ alcohol solution, and the third - to a solution containing $0.4 \mathrm{~g} / \mathrm{l}$ caffeine, the fourth (control) - only to water.

Alcohol preference was measured using a standard two bottle test before the experiment and each subsequent month during the whole experiment after a 24 hours deprivation. This was made by placing the animals into a single cage and offering them two waterers: one contained water, and the other $10 \%$ ethanol solution. The quantity of liquid taken from different waterers was estimated during a 15 minutes time period.

Behavior parameters were estimated before and every month of the experiment using "Open field". The "Open field" test allows seeing animals with high or low locomotion and emotional levels. The setting is a square, divided into smaller squares area $0.5 \times 0.5 \mathrm{~m}$ bounded by non-transparent $0.8 \mathrm{~m}$ borders around the periphery. Number of crossed squares, vertical points, urination and defecation, latent period of leaving the first square, and grooming were registered during a 5 minute period.

After 6 months of the experiment the anxiety and behavioral activity were investigated in the "Suok test". "Suok test" is an alley divided into segments $5 \mathrm{~cm}$ wide and placed at a height of $50 \mathrm{~cm}$ upon the floor [23]. A series of parameters which reflected motor and investigative activities, as well as anxiety was estimated during a 5-minute time period. These parameters also included: the number of crossed segments, the vertical activity, peep down, orientations, the latent period of exit from the starting square and the number of feet from slipping, falling, urinations and defecations. Reduction indicators of motor and behavioral activity (crossings, the vertical activity, peep down, orientations), and an increase in the number of slips, falls, urinations and defecations are reporting increasing levels of anxiety in animals.

The order of the tests was 1) two-bottle test was conducted before and each month of the experiment; 2) Next day after the "two-bottle" test the "open field" test was conducted before and each month of the experiment; 3) "Suok-test" in the end of the experiment. The light intensity was 60 Watt from the lamp 1.5 meter above the open field set or "Suok-test" set. The persons doing the testing were blind to experimental conditions, i.e. they did not know what kind of liquor was consumed by the rat. All rats were marked by another collaborator. The female estrous cycle stage was not taken into consideration.

Statistical analysis was performed using ANOVA Fisher LSD test. The experiments were carried out in accordance with the requirements of the Commission on Bioethics and in compliance with international standards GLP («Good Laboratory Practice»).

\section{Results}

Before and after the first month of the experiment all male rats have shown the low level of ethanol consumption in two-bottle test, compared to control (Figure 1). In the third, fourth and fifth months the ethanol preference has increased in all animals excepting the controls, although these differences were only a tendency. After sixth month of the experiment the same tendency was observed: the caffeine + ethanol rats consumed more 
ethanol in two-bottle test than before the experiment and compared to animals of the other groups.

In female rats the ethanol consumption in two-bottle test was also low before the experiment (Figure 2). A month later, the ethanol preference has increased in all rats except controls. The ethanol consumption in the "two-bottle" test was significantly higher in all experimental groups compared to the control group after the second month (ethanol + caffeine $p<0.057$, ethanol $p<$
0.058 , caffeine $p<0.016)$ and after the third month of the experiment (ethanol + caffeine $p<0.0006$, ethanol $p$ $<0.0013$, caffeine $p<0.0039$ ). After the fifth month ethanol preference was significantly increased in ethanol+caffeine and ethanol groups compared with animals consuming caffeine $(p<0.015, p<0.052)$ and controls $(p<0.00015, p<0.0006)$. After 6 months, the ethanol + caffeine female rats have demonstrated significantly higher ethanol preference in two-bottle test $(p<0.077$

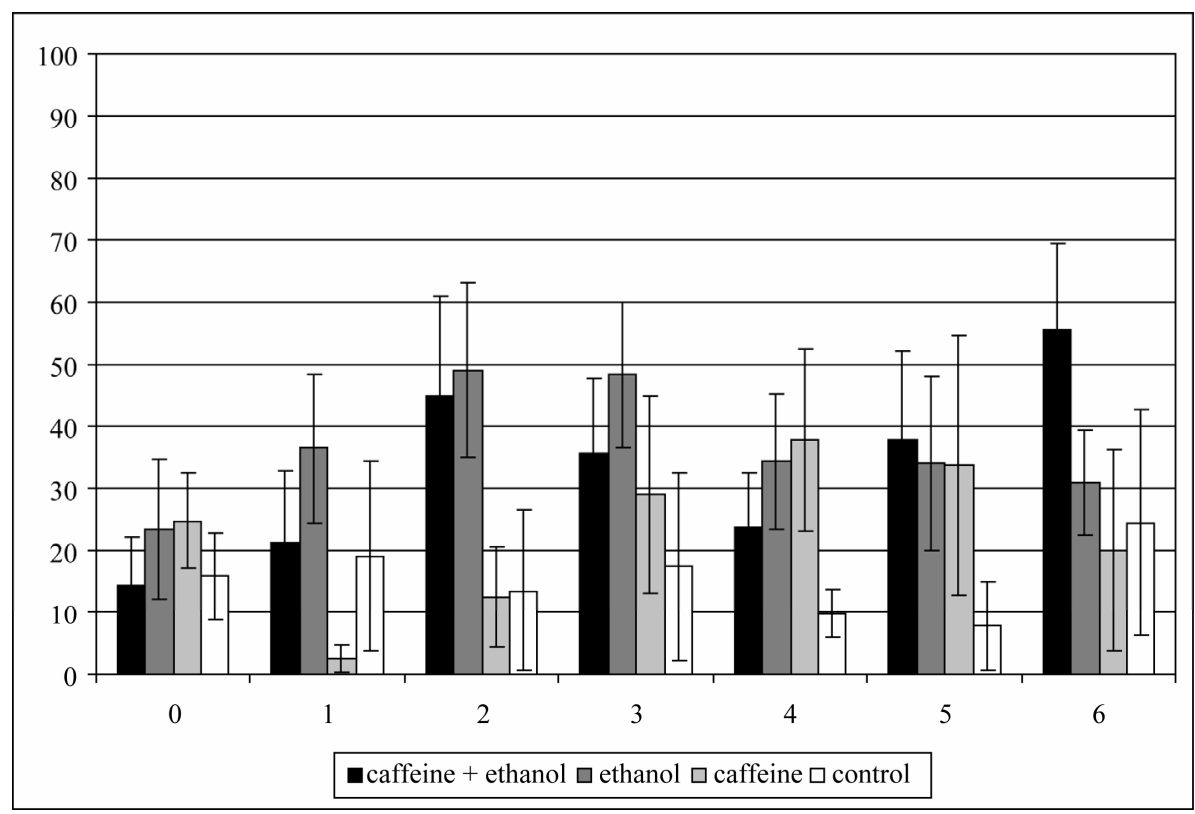

Figure 1. Consumption of ethanol solution in the "two-bottle" test in male rats. The ordinate axis shows the percentage of consumed ethanol from the total amount of liquid consumed in the test (data are expressed as the arithmetic mean value and the standard error of the mean). Along the horizontal axis—months of the experiment.

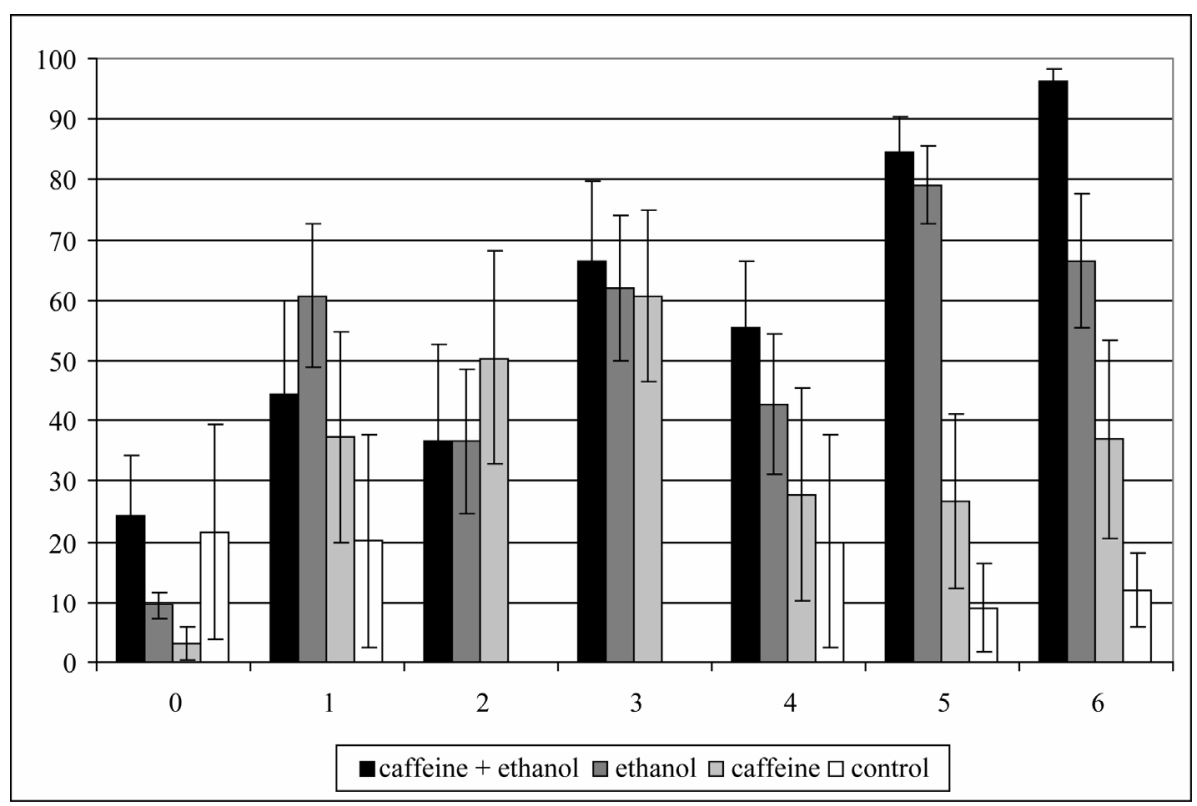

Figure 2. Consumption of ethanol solution in the "two-bottle" test in female rats. All indications as in Figure 1. 
compared with ethanol, $p<0.0012$ compared with caffeine, $p<0.000016$ compared with water). The lower preference was in ethanol rats, than in caffeine, than in controls.

Thus, from the second to fourth months of the experiment the ethanol consumption was increased in rats of both sexes in the two-bottle test, excepting the control animals. The greatest ethanol preference was observed in the groups drinking caffeine with ethanol.

It is of interest, that the highest difference was observed in male and female rats, consuming ethanol with caffeine $(p<0.000050)$. The female rats, drinking ethanol, have preferred alcohol in two-bottle test more than male rats, too $(p<0.034)$. The caffeine and control male and fe- male animals didn't differ statistically (Figure 3).

ANOVA results are presented in Table 1.

In the open field test male rats showed higher behavioral activity before the experiment (Figure 4). The behavioral activity included the number of crossed squares and the vertical activity. In subsequent months, this activity decreased, which is likely due to habituation of animals to test conditions and a reduction of exploratory activity. The rats consumed caffeine with ethanol were significantly more active than other rats on the third and sixth months of experience.

Female rats also demonstrated the highest behavioral activity in the open field during the first measure before the experiment (Figure 5). Then, behavioral activity has

Table 1. ANOVA results of factor ("substance”, “time” and "sex") influence on ethanol consumption in the two-bottle test.

\begin{tabular}{cccccc}
\hline Factors & SS & Degr. of & MS & $\boldsymbol{F}$ & $\boldsymbol{p}$ \\
\hline substance & 61115.4 & 3 & 20371.8 & 17.0901 & 0.000000 \\
time & 24780.8 & 6 & 4130.1 & 3.4648 & 0.002440 \\
sex & 13815.2 & 1 & 13815.2 & 11.5897 & 0.000740 \\
subst*time & 29691.4 & 18 & 1649.5 & 1.3838 & 0.136176 \\
subst* ${ }^{*}$ sex & 9538.9 & 3 & 3179.6 & 2.6674 & 0.047626 \\
time*sex & 9188.8 & 6 & 1531.5 & 1.2848 & 0.263432 \\
subst*ime*sex & 21944.9 & 18 & 1219.2 & 1.0228 & 0.432945 \\
Error & 416016.0 & 349 & 1192.0 & & \\
\hline
\end{tabular}

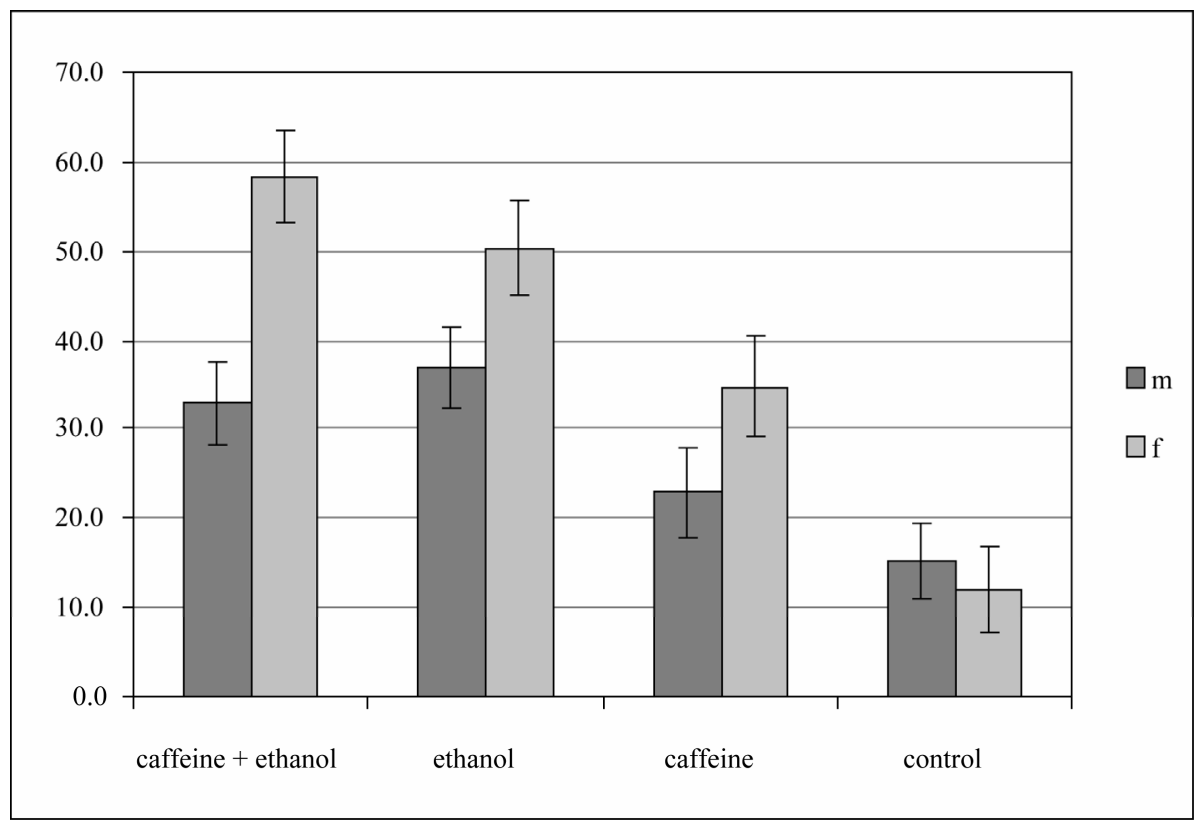

Figure 3. Consumption of ethanol in the "two-bottle" test by male and female rats. The ordinate axis shows the percentage of consumed ethanol from the total amount of liquid consumed in the test (data are expressed as the arithmetic mean value and the standard error of the mean). The abscissa - groups of rats consuming different substances. Left bar—male rats, right bar -female rats. 


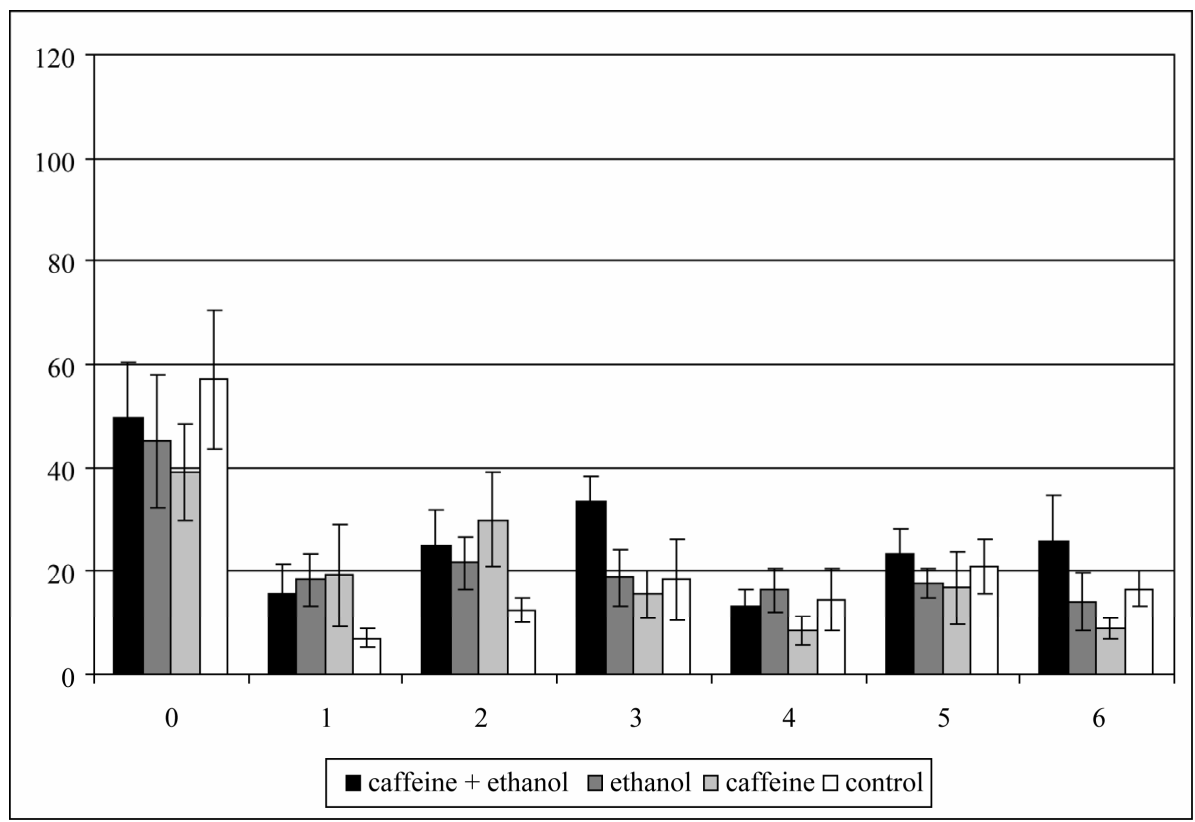

Figure 4. Total behavioral activity in the "open field” test in male rats. Along the horizontal axis-months of the experiment; the ordinate - the total behavioral activity (number of crossed squares and vertical activity), in points.

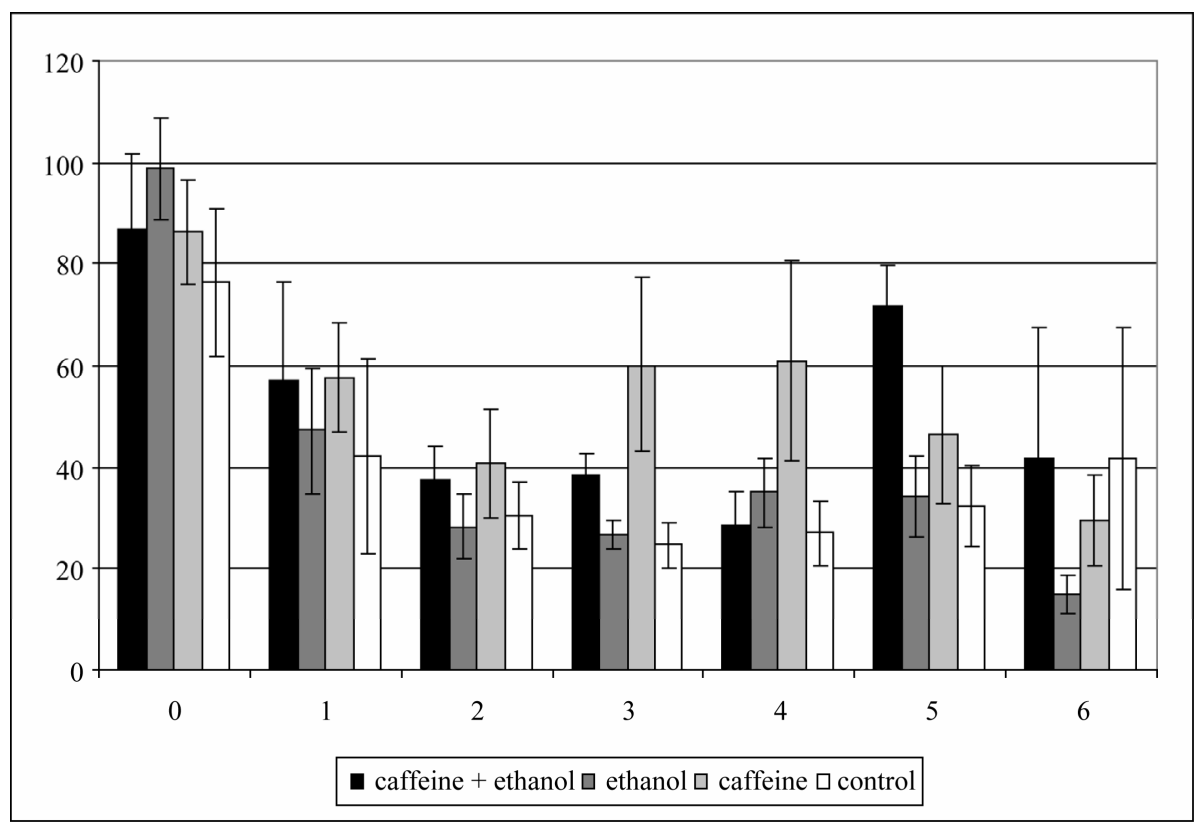

Figure 5. Total behavioral activity in the “open field” test in female rats. All indications as in Figure 3.

decreased in all groups. On the third and fourth months of the experiment behavioral activity was significantly higher in rats taking caffeine, than in other groups. By the fifth month of the experiment the activity significantly increased in rats consuming alcohol and caffeine. It was significantly higher than in other groups (receiving ethanol $p<0.002$, caffeine $-p<0.052$, control $-p<$ $0.0002)$. After 6 months of the experiment, the behaveioral activity was similar in animals receiving ethanol with caffeine, caffeine and control animals and was significantly lower in rats drinking ethanol $(p<0.05$ as compared to receiving ethanol with caffeine).

Thus, both male and female consumed caffeine with alcohol showed a significantly higher behavioral activity in the open field during different experimental months: the males in the third and sixth, while females only in the fifth month of the experiment. Females, taking caffeine, showed higher behavioral activity in the middle of the 
experiment, in contrast to males.

ANOVA results are presented in Table 2.

After 6 months of the experiment, male rats received caffeine with ethanol demonstrated higher behavioral activity in "Suok test" than animals receiving ethanol $(p<$ 0.08) (Figure 6). Behavioral activity in this test was measured by the number of crossed segments, vertical postures, orientations and peeking. The data obtained in "Suok test" are similar to those in the open field. Anyway the conditions of "Suok test" are more stressful than in the open field.

In female rats consumed caffeine behavioral activity in the "Suok test" was significantly higher $(p<0.0030$ compared to receiving ethanol + caffeine, $p<0.0050-$ ethanol and $p<0.00006-$ control).

The level of anxiety, including the slips, falls, urina- tions and defecations, did not differ in all male groups (Figure 7). Anxiety level was significantly higher compared to controls in female rats, receiving ethanol + caffeine $(p<0.022)$ and ethanol $(p<0.013)$.

\section{Discussion and Conclusions}

The results of two-bottle test suggest that both psychoactive substances: caffeine, ethanol and their combination leads to the increase of ethanol preference in two months from the start of the experiment. It is known that single dose caffeine affects the preference of ethanol intake: according to some authors' it increased [13], while according to the others caffeine reduced ethanol consumption [12]. During combined chronic intake of both substances one can observe not only the mutual effect of

Table 2. ANOVA results of factor ("substance”, “time” and "sex") influence on behavioral activity in the "open field" test.

\begin{tabular}{cccccc}
\hline Factors & SS & Degr. of & MS & $\boldsymbol{F}$ & $\boldsymbol{p}$ \\
\hline substance & 6592.8 & 3 & 2197.6 & 3.3718 & 0.018719 \\
time & 62980.2 & 6 & 10496.7 & 16.1053 & 0.000000 \\
sex & 47958.2 & 1 & 47958.2 & 73.5830 & 0.000000 \\
subst*time & 13893.6 & 18 & 771.9 & 1.1843 & 0.271572 \\
subst*sex & 2551.7 & 3 & 850.6 & 1.3050 & 0.272641 \\
time*sex & 6892.7 & 6 & 1148.8 & 1.7626 & 0.106019 \\
subst*time* sex & 10600.1 & 18 & 588.9 & 0.9035 & 0.574591 \\
Error & 220945.3 & 339 & 651.8 & & \\
\hline
\end{tabular}

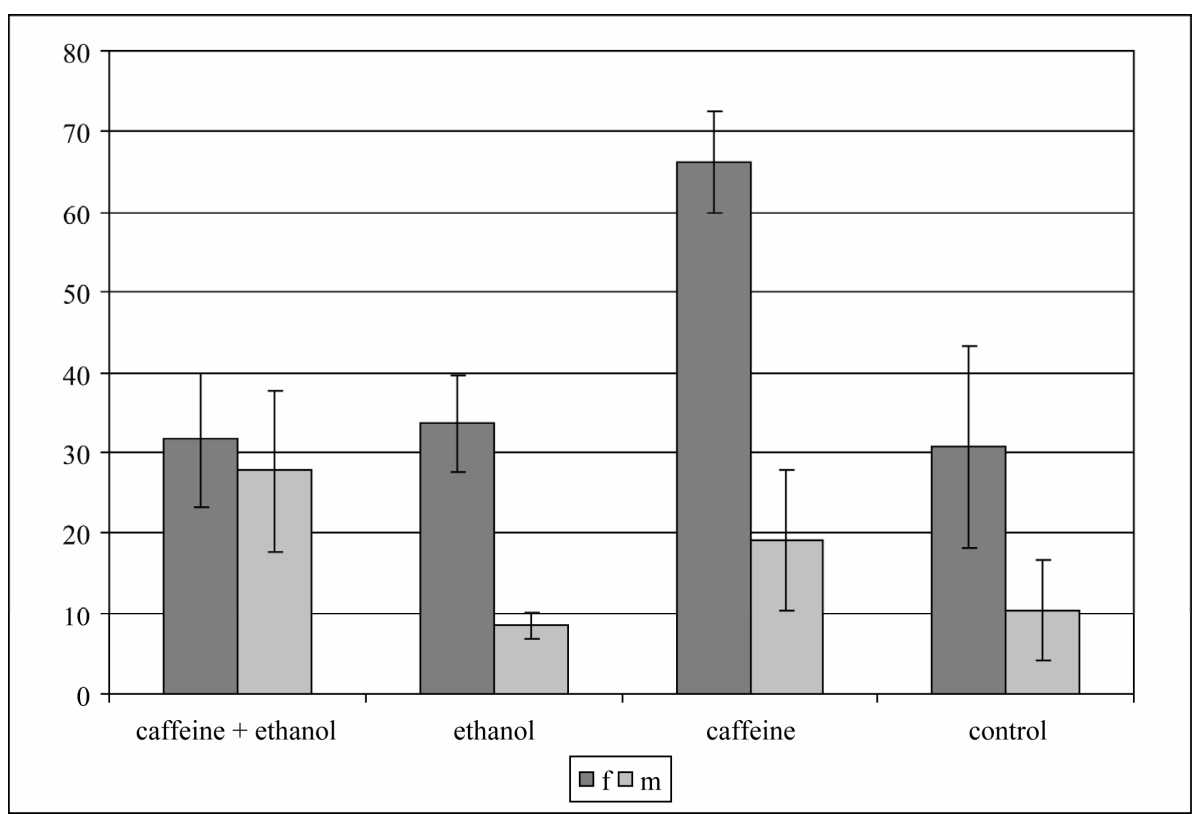

Figure 6. Behavioral activity in the "Suok test" after 6 months of the experiment in male and female rats. Left bar-male rats, right bar-female rats. The ordinate-behavioral acts, in points. 


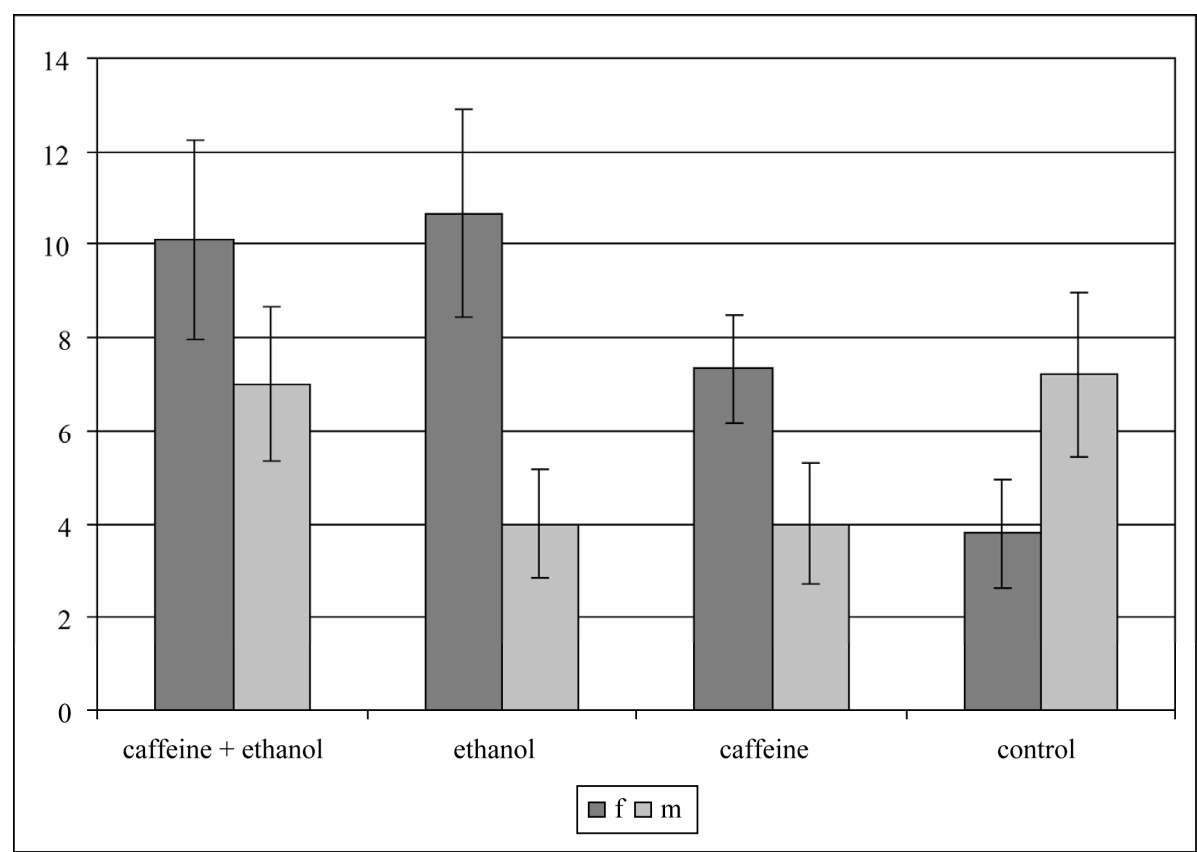

Figure 7. Anxiety in the "Suok test" after 6 months of the experiment in male and female rats. All indications as in Figure 6.

ethanol and caffeine, but the effect changes of each substances because of their interaction. It is important that alcohol preference was higher in female rats drinking caffeine with ethanol and ethanol compared to males. This fact demonstrates higher development of alcohol preponderance in females consuming stimulant-ethanol mixture and pure ethanol solution.

It is known that the effects of caffeine are associated with the adenosine receptor blocking which induces changes in other neurotransmitter systems: dopamine, serotonin, noradrenalin and acetylcholine [24]. It was observed that the acute alcohol introduction changes the activity of all monoaminergic systems [25]. It was shown that serotonin and noradrenalin systems play a modulating role in the development of tolerance to ethanol [26]. Increased dopamine stimulates ethanol consumption, while increased serotonin reduces it [27]. It is supposed that caffeine, ethanol or their combination effects mediated via monoaminoergic system lead to the increase of alcohol consumption in experimental animals compared to water control rats. In all animals received caffeine and ethanol combination, the alcohol preference increased earlier than in animals consuming pure $10 \%$ ethanol. The rats received only caffeine does not exhibit a persistent preference for alcohol. Perhaps, in the case of combined caffein and ethanol consumption the more rapid increase in tolerance occurred, and as a consequence the increase of alcohol preference. Earlier the sensitivity to nicotine and cocaine as a result of prior caffeine intake has been described in experimental animals [28].

The obtained increase of behavioral activity in caf- feine and ethanol + caffeine rats agrees with Ferreira with colleagues, [17] data that.the administration of energy drink alone has increased the locomotor activity of mice and facts that reduction of activity observed after high doses of ethanol was antagonized by energy drink.

In behavioral experiments (open field and Suok tests) both gender similarities and differences were revealed. Obviously that animal behavior in both tests is related not only to the motor and research activity, but to emotional state as well. Female rats consuming caffeine + ethanol and caffeine were significantly more active compared to the other female groups. All male groups did not reveal this difference. It may be explained by higher anxiety level among caffeinated females. Pervious investigations have considered that anxiety level does positively correlate with alcohol intake [29,30] It is known that female alcoholism is often correlated with affective disorders [31], which is associated with sero- tonin deficiency $[32,33]$.

Thus, it can be concluded that:

- A long-time intake of caffeine, ethanol and their combination has led to the increase of alcohol preference both in male and female rats;

- Alcohol preference was higher in female rats consuming caffeine with ethanol and pure ethanol solution compared to male rats;

- Alcohol preference was formed earlier in rats consumed combination of caffeine with ethanol, later on in rats consumed ethanol. In animals consumed caffeine the strong alcohol preference did not form up to the end of the experiment; 
- Behavioral activity significantly increased in female consumed caffeine and caffeine with ethanol, compared to animals received ethanol and controls. Similar tendency was observed in male rats;

- The anxiety level was significantly higher in females rats in all experimental groups compared to controls, while males did not demonstrate increased anxiety.

\section{References}

[1] Prescript No. 46 of 29.06.2009. "On Oversight of Alcoholic Beverages. Federal Service for Supervision of Consumer Rights Protection and Human Welfare," Registered in the Russian Ministry of Justice on 31.08.2009, registration number 14644, (In Russian).

[2] F. E. Sheregi and A. L. Aref'ev, "Estimation of Addiction Situation in Children, Adolescents and Youth. A Report," Optim Group Edition, Moscow, 2003, (In Russian).

[3] M. C. O'Brien, T. McCoy, S. D. Rhodes, A. Wagoner and M. Wolfson, "Caffeinated Cocktails: Get Wired, Get Drunk, Get Injured," Academic Emergency Medicine, Vol. 15, No. 5, 2008, pp. 453-460.

[4] A. Oteri, F. Salvo, A. P. Caputi and G. Calapai, "Intake of Energy Drinks in Association with Alcoholic Beverages in a Cohort of Students of the School of Medicine of the University of Messina," Alcoholism: Clinical and Experimental Research, Vol. 31, No. 10, 2007, pp. 16771680. doi:10.1111/j.1530-0277.2007.00464.x

[5] J. Istvan and J. D. Matarazzo, "Tobacco, Alcohol, and Caffeine Use: A Review of Their Interrelationships," Psychological Bulletin, Vol. 95, No. 2, 1984, pp. 301-326. doi:10.1037/0033-2909.95.2.301

[6] L.T. Kozlowski, J. E. Henningfield, R. M. Keenan, H. Lei, G. Leigh, L. C. Jelinek, M. A. Pope and C. A. Haertzen, "Patterns of Alcohol, Cigarette, and Caffeine and Other Drug Use in Two Drug Abusing Populations," Journal of Substance Abuse Treatment, Vol. 10, No. 2, 1993, pp. 171179. doi:10.1016/0740-5472(93)90042-Z

[7] S.E.Ferreira, M. T. de Mello, S. Pompeia and M. L.de Souza-Formigoni, "Effects of Energy Drink Ingestion On Alcohol Intoxication," Alcoholism: Clinical and Experimental Research, Vol. 30, No. 4, 2006, pp. 598-605. doi:10.1111/j.1530-0277.2006.00070.x

[8] C.J. Reissig, E.C. Strain and R. R. Griffiths, "Caffeinated Energy Drinks-A Growing Problem," Drug and Alcohol Dependence, Vol. 99, No. 1-3, 2009, pp. 1-10. doi:10.1016/j.drugalcdep.2008.08.001

[9] K. E. Miller, "Energy Drinks, Race, and Problem Behaviors among College Students," Journal of Adolescent Health, Vol. 43, No. 5, 2008, pp. 490-497. doi:10.1016/j.jadohealth.2008.03.003

[10] A. M. Arria, K. M. Caldeira, S. J. Kasperski, K. B. Vincent, R. R. Griffiths and K. E. O'Grady, "Energy Drink Consumption and Increased Risk for Alcohol Dependence," Alcoholism: Clinical and Experimental Resear, Vol. 35, No. 2, 2011, pp. 365-375. doi:10.1111/j.1530-0277.2010.01352.x
[11] A. M. Arria, K. M. Caldeira, S. J. Kasperski, K. E. O'Grady, K. B. Vincent, R. R. Griffiths and E. D. Wish, "Increased Alcohol Consumption, Nonmedical Prescription Drug Use, and Illicit Drug Use Are Associated with Energy Drink Consumption among College Students," Journal of Addiction Medicine, Vol. 4 No. 2, 2010, pp. 74-80.doi:10.1097/ADM.0b013e3181aa8dd4

[12] M. A. Dietze and P. J. Kulkosky, "Effects of Caffeine and Bombesin on Ethanol and Food Intake," Life Sciences, Vol. 48, No. 19, 1991, pp. 1837-1844. doi:10.1016/0024-3205(91)90239-8

[13] D. Kunin, S. Gaskin, F. Rogan, B.R. Smith and Z. Amit, "Caffeine Promotes Ethanol Drinking in Rats. Examination Using a Limited-Access Free Choice Paradigm," Alcohol, Vol. 21, No. 3, 2000, 271-277. doi:10.1016/S0741-8329(00)00101-4

[14] D. Gulick and T. J. Gould, "Effects of Ethanol and Caffeine on Behavior in C57BL/6 Mice in the Plus-Maze Discriminative Avoidance Task," Behavioral Neuroscience, Vol. 123, No. 6, 2009, pp. 1271-1278. doi: $10.1037 / \mathrm{a} 0017610$

[15] C. L. Drake, T. Roehrs, L. Turner, H. M. Scofield and T. Roth, "Caffeine Reversal of Ethanol Effects on the Multiple Sleep Latency Test, Memory, and Psychomotor Performance," Neuropsychopharmacology, Vol. 28, No. 2, 2003, pp. 371-378. doi:10.1038/sj.npp.1300026

[16] M. T. Fillmore, "Alcohol Tolerance in Humans Is Enhanced by Prior Caffeine Antagonism of Alcohol-Induced Impairment," Experimental and Clinical Psychopharmacology, Vol. 11, No. 1, 2003, pp. 9-17. doi:10.1037/1064-1297.11.1.9

[17] S. E. Ferreira, I. M. Hartmann Quadros, A. A. Trindade, S. Takahashi, R. G. Koyama, M. L. Souza-Formigoni, "Can Energy Drinks Reduce the Depressor Effect of Ethanol? An Experimental Study in Mice," Physiology \& Behavior, Vol. 82, No. 5, 2004, pp. 841-847.

[18] Y. D. Pometov, V. P. Nujni, A. V. Kovaleva and I. V. Demshina, "Evaluation of Physiological Effects Caused by Taking a Mixture of 'Energy' Drinks and Spirits in Studies Involving Men-Volunteers," Voprosy Narcologii (Addiction Issues), No. 6, 2004, pp. 52-58, (In Russian).

[19] J. L. Temple, A. M. Bulkley, L. Briatico and A. M. Dewey, "Sex Differences in Reinforcing Value of Caffeinated Beverages in Adolescents", Behavioural Pharmacology, Vol. 20, No. 8, 2009, pp. 731-741. doi:10.1097/FBP.0b013e328333b27c

[20] B. Malinauskas, V. G. Aeby, R. F. Overton, T. CarpenterAeby and K. A. Barber, "Heidal Survey of Energy Drink Consumption Patterns among College Students," Nutrition Journal, Vol. 6, 2007, pp. 35-41. doi:10.1186/1475-2891-6-35

[21] A. Y. Egorov, "Early Alcohol Abuse and Alcoholism in Russia” In: K. Kurtakko, M. Rantaniemi and P. Holappa, Eds., Research, Education and Environment in the Barents Region, Lapland University Press, Rovaniemi, 2004, pp. 102-112.

[22] J. A. Tur, M. S. Puig, A. Pons and E. Benito, "Alcohol Consumption among School Adolescents in Palma de Mallorca," Alcohol, Vol. 38, No. 3, 2003, pp. 243-248. 
[23] A.V. Kalueff, T. Keisala, A. Minasyan, S. R. Kumar, J. L. LaPorte, D. L. Murphy and P. Tuohimaa, "The Regular and Light-Dark Suok Tests of Anxiety and Sensorimotor Integration: Utility for Behavioral Characterization in Laboratory Rodents," Nature Protocols, Vol. 3, No. 1, 2008, pp. 129-136. doi:10.1038/nprot.2007.516

[24] B. B. Fredholm, K. Battig, J. Holmen, A. Nehlig and E. E. Zvartau, "Actions of Caffeine in the Brain with Special Reference to Factors that Contribute to Its Widespread Use," Pharmacological Reviews, Vol. 51, No. 1, 1999, pp. 84-125.

[25] P. D. Shabanov and S. Y. Kalishevich, "Biology of Alcoholism," LAN' Publishing House, Saint-Petersburg 1998. (In Russian)

[26] G. E. Alcohol and Health, 7th Spec. Rep. USA Congr, Rockville, 1990, p. 289.

[27] P. D. Shabanov "Drug and Alcohol Abuse: A Practical Guide for Physicians," Geotar-Med, Moscow, 2003, (In Russian).

[28] J. L. Temple "Caffeine Use in Children: What We Know, What We Have Left to Learn, and Why We Should Worry," Neuroscience \& Biobehavioral Reviews, Vol. 33, No. 6, 2009, pp. 793-806. doi:10.1016/j.neubiorev.2009.01.001

[29] S. L. Blatt and R. N. Takahashi, "Experimental Anxiety and the Reinforcing Effects of Ethanol in Rats," Brazilian Journal of Medical and Biological Research, Vol. 32, No. 4, 1999, pp. 457-461. doi:10.1590/S0100-879X1999000400013

[30] R. Spanagel, A. Montkowski, K. Allingham, T. Stöhr, M. Shoaib, F. Holsboer and R. Landgraf, "Anxiety: A Potential Predictor of Vulnerability to the Initiation of Ethanol Self-Administration in Rats," Psychopharmacology, Vol. 122, No. 4, 1995, pp. 369-373. doi:10.1007/BF02246268

[31] R.D. Anita and M. C. Rosa, "Prospective Study of Depression and the Risk of Heavy Alcohol Use in Women," The American Journal of Psychiatry, Vol. 157, 2000, pp. 751-758. doi:10.1176/appi.ajp.157.5.751

[32] D. H. Overstreet, A. H. Rezvani and D. S. Janowsky, "Genetic Animal Models of Depression and Ethanol Preference Provide Support for Cholinergic and Serotonergic Involvementin Depression and Alcoholism," Biological Psychiatry, Vol. 31, No. 9, 1992, pp. 919-936. doi:10.1016/0006-3223(92)90118-J

[33] C. A. Stockmeier, "Neurobiology of Serotonin in De- pression and Suicide," Annals of the New York Academy of Sciences, Vol. 835, 1997, pp. 220-232. doi:10.1111/j.1749-6632.1997.tb52362.x 